revolver about nine o'clock that evening. The wound ran diagonally from about the centre of the temple backwards, outwards, and a little upwards-i.e., towards the npper part of the left temporal fossa. With the probe metal could be distinctly felt at no great distance from the point of entry. There were no cerebral symptoms, except vomiting.

March 23rd.-The operation was performed at 1.30 A.M. One-fifth of a grain of morphia was administered subcutaneously and chloroform commenced ten minutes afterwards. A horseshoe-shaped flap was turned downwards, exposing the bullet wound in the skull and the bone to the left of it. The track of the bullet was very oblique and towards the left. A small piece of lead was found immediately beneath the periosteum at the opening in the bone. A circle of bone, the size of a shilling, was removed from the left side of the bullet wound, and the first inch of the bullet track thus exposed. It was grimy and contained splinters of bone. It was carefully cleansed. A silver probe found its own way along the track till its point impinged on the inner surface of the cranium in the temporal region. There an irregularity could be felt. A fine pair of bullet forceps was passed down to this, which proved immovable, and was therefore left alone. A fine drainage-tube was passed in (for about four inches and a half), having a double loop of catgut in it. The soft parts of the wound were scraped and cleansed of grime. Iodoform crystals and gauze dressings were applied. The patient vomited frequently during the dressing and several times during the night.

24th. -Sick again this morning. Quite sensible. Bandage relaxed. Morning temperature $99^{\circ}$, evening $101 \cdot 2^{\circ}$.

25th. - A little headache. No vomiting since noon yesterday. Quiet night. Morning temperature $100^{\circ}$, evening $100 \cdot 6^{\circ}$

26th.-Bowels freely opened after enema. No more vomiting. Continues sensible. Temperature normal. Wound dressed in the evening. Not much oozing into dressing. Wound looks well, but there is a little puffiness over the forehead and eyelids. Catgut loop withdrawn from inside the drainage-tube (which was not blocked). Tube drawn out a little and shortened three-quarters of an inch. Same dressing repeated with a small sponge over it. Ice-bag continued. No pain. Morning temperature normal, evening $99 \cdot 8^{\circ}$.

27th.-No pain. Taking milk and beef - tea freely. Morning temperature $99 \cdot 8^{\circ}$, evening $99 \cdot 8^{\circ}$.

April 4th.-Distinct pulsation can be felt over the trephine wound; dressed for the third time and drainage-tube removed. A sponge was strapped over the dressing, the strapping encircling the whole head. Low diet still continued.

16th.-Dressing folt a little uncomfortable. Temperature rose in the evening to $100^{\circ}$ for the first time since the second day after operation.

17th.-A drop of atropine having been placed in the left eye preparatory toophthalmoscopic examination, the patient became angry and much disturbed, probably through misunderstanding and fright, and would not permit anything further to be done.

On the 23rd meat diet was given for the first time, and on the 28 th he was discharged.

Remarks by Mr. KEETLEY.-He has been seen many times since both by myself and Dr. Gardner of Mill-hill Park, who attends his family. There of course remains a cutaneous scar and a deficiency in the bone, but otherwise he is well. The operation, including the trephining itself, was done as much with a view to cleansing and asepticising the track as with the hope of extracting the bullet. The result was that, instead of there being left a narrow, dirty, perhaps inflamed and sloughing canal, containing burnt powder and bone splinters, and ending at one extremity in the brain, there was a perfectly clean and aseptic tube of flesh and blood conducting a small soft drainage-tube down the bullet track in the brain, perhaps to its termination. A second point to be noticed is that the patient was kept over a month in bed on milk and beef-tea diet. The importance of keeping such a case quiet and unexcited for a lono time is obvious. No one hesitates to keep a case of typhoid fever on prolonged milk diet. This boy was suffering from a condition much more dangerous and incomparably less exhausting than typhoid fever. Next to asepsis the prime indication was to secure quiet, physically and physiologically, and, especially in a healthy boy of fourteen, an unstimulating diet is not only antiphlogistic, but also helps to keep the patient tame and obedient. Where is the part of the bullet (almost the whole of it), and is it likely to cause future mischief? I would first ask-Is it possible for a narrow revolver bullet to pass through the motor centres in the cerebral cortex, or through the subcortical fibres rarliating to them, withoutcausing either paralysis or spasms? I should like to hear the opinions of Professors Horsley and Macewen on this point. I myself think it may be possible, but that it is not likely. I therefore think that the bullet in Edward H-C's case lies. anterior to the motor area, and that it is lodged near the base of the left middle frontal convolution, I hope partly embedded in the dura mater and frontal bone there, and encysted. If the bullet had not been fixed, would it not. before now have gravitated downwards during the day and backwards during the night? Such gravitation should haveproduced symptoms. T'en months have now passed over in safety. The bullet may by this time have slipped down to the roof of the orbit, and there become fixed and harmless. But if it continues to move backwards and downwards, sooner or later symptoms should appear, especially aphasia, and (much less likely) facial paralysis of cortical origin, or else some affection of the cerebral nerves at the base of the brain. The patient has the advantage of being under the continued observation of Dr. W. T. Gardner; he can be easily and promptly returned to the hospital at any time should any symptoms occur to localise the bullet, and I hope he is in a fair way to remain one of the few cases in which a bullet has lodged in the brain and practically complete recovery taken place without extraction of the missile. I should add that the left temporal fossa and its neighbourhood have been repeatedly exanined, with negative results.

\section{MARGATE COTTAGE HOSPITAL.}

AMPUTATION OF FOOT, WITH RAPID UNION, IN SPITE OF SYPHILIS, GOUT, AND DELIRIUM TRENENS; REMARKS.

\section{(Under the care of Mr. BerTram ThORNTON.)}

THIs case presents an example of recovery from amputation of the leg when many constitutional conditions unfavourable to rapid healing were present. Mrr. Thornton attributes the success chiefly to the antiseptic treatment employed.

The patient, a debilitated man, aged thirty-eight, was admitted early in February, suffering from disease of the right tarsus, which eventually turned out to be of a tertiary specific origin. Mr. Treves, who first had charge of the case, made incisions into the foot and crot away some necrosed bone on Feb. 22nd. In spite of the operation, the foot remained swollen and inflamed, and the evening temperature varied between $100^{\circ}$ and $101^{\circ}$. As the man was rapidly going to the bad, and the foot began steadily to get worse, it was decided to amputate in spite of the man's unfavourable condition, for already he had characteristic gonty inflammation of several joints. On March 3rd, in Mr. Treves absence, $\mathrm{Mr}$. Thornton amputated the foot three inches above the joint by Teale's method, using the ordinary antiseptic precautions; two small drainage-tubes were inserted at the angles of the wound, and iodoform oil and liberal absorbent wool dressings applied. The amputated foot was totally disorganised, and had the horribly offensive odour so often met with in syphilitic bone disease. The amputation wound healed steadily and well, and by the eighth day was firmly healed, with the exception of two small superficial places at the angles of the wound.

Remarks by $\mathrm{Mr}$. Thornton.--The interesting features are-firstly, the extreme debility of the patient; secondly, the syphilitic condition leading to the eperation, which condition was proved by the history of the patient and the evidence of scars about the legs; thirdly, the gouty inflammation of various joints before the operation and for a fortnight afterwards; and, fourthly, the onset of alcoholic delirium, with visions of a big black dog \&c., two days after the operation, lasting more or less for a week or ten days. To add to the patient's danger there had just been a very bad case of erysipelas in the adjoining ward, from which he was mercifully spared. It is rare that an amputation should heal so readily under such extreme and varied pathological difficulties. In this case there were two more interesting features which are worthy of note, the first being the formation of an abscess extending from the head of the fibula to within two inches of the operation wound, with which it had no connexion whatever. It appeared to me 
that it might be due to the pressure of the Esmarch's indiarubber tourniquet, which was used with the ordinary amount of tightness at the operation over the old specific scars. Eighteen days after the amputation the patient was anæsthetised, and I opened the abscess above and below, and, as a second interesting feature, I pulled out a firm pyogenic membrane, which had the appearance and consistency of the foetal membranes. A drainage-tube was passed through the cavity of the abscess, and membrane was discharged for about a week afterwards ; and in another ten days the abscess cavity was wbliteraterl and the two wounds quite healed. The case presented so many features of interest that I thought it worth recording. The surgeon has frequently to risk operation in syphilitic and alcoholic cases, but he is rarely called upon to operate in acute gout, and more rarely still in the presence of all three, to say nothing of the dread shadow of erysipelas in the background. The fact that this man successfully ran the gauntlet of all these foes speaks well for the blessings of antiseptic surgery, or at any rate for the vitality of the human race at the close of the nineteenth century.

\section{筑otices of 策oofis.}

A Treatise on Chemistry. By Sir H. E. Roscoe, F.R.S., and C. Schorlemmer, F.R.S. Vol. III. : The Chemistry of the Hydrocarbons and their Derivatives, or Organic Chemistry. Part V. London and New York: Macmillan and Co. 1889. - This is the eighth volume of the great English work so well known to and so highly valued by English chemists. It is hard to guess when it will be completed, as there are still many important groups of compounds to be described; and we trust that a final volume, or at any rate an appendix, will give more detailed information in regard to physical and particularly to thermal chemistry, than has yet been afforded. The great merits of the treatise are its convenient classification and lucid style, the numerous references to original memoirs with which it is illustrated, and the admirable historical sketches, sometimes extending backwards to Ancient Egypt, Assyria, India, Arabia, Greece, and Italy, with which every important substance is introduced. This last feature gives constant interest as well as additional value to the book, and a good example is afforded in the present volume, where the history of discovery in regard to the terpenes and camphors is traced from Dioscorides and Pliny to Tilden and Shenstone in our own day. Each part - that is, each volumeof the organic portion of the book is complete in itself, and forms a monograph on some important series of compounds. The last two volumes (Parts 3 and 4) have been devoted respectively to the derivatives of benzene and of toluene and xylene. The present volume (Part 5) begins with ethyl-benzene and the styrolene group, in which amygdalin and isatin are included. It would perhaps have been more convenient if this group could have found a place in the previous volume. Then follows the cumene group. Nine hydrocarbons having the formula $\mathrm{C}_{9} \mathrm{H}_{12}$ are now known, and they, as well as their leading derivatives, are sufficiently described. Cinnamic acid is at present the most interesting member of the group. About half way through the book we are introduced to the aromatic hydrocarbons containing more than nine atoms of carbon-the cymenes, of course, coming first. They are chiefly interesting because they almost certainly include the highly inportant terpenes and camphors, as well as caoutchouc and gutta-percha. The volume ends with an account of the last-named bodies and one or two allied substances.

Lessons in Gynocology. By WILLTAM Goodell, A.M., M.D. Third Edition. Philadelphia. 1887.- The review of a third edition of this book concerns principally the question of its revision to the level of present knowledge. This cannot be said to have been accomplished, notably in the case of pathology; for we find the old and incorrect statements as to the effects of flexions on the uterine circulation, as to the pathology of uterine cancer, and as to many other important diseases. Since practice must be based on pathology, our criticism is not merely pedantic. Some of the earlier chapters, being apparently clinical demonstrations on minor ailments, are graphic and practical, and there is much that is good in the work. No book, however, can be a sound guide for the student and practitioner unless it is abreast of the times; and in this respect the present work shares the fate of many others, when the author becomes too busy to read.

The Neuroses of the Genito-urinary System in the Male, with Sterility and Impotence. By Dr. R. UltzmanN, Professor of Genito-urinary Diseases in the University of Vienna. Translated by GARDNer W. ALLEN, M.D., Surgeon in the Genito-urinary Department, Boston Dispensary. Boston : Cupples and Hurd. 1889. - The title of the work fully describes its scope, and the name of the author is ample guarantee for its thoroughness and systematic completeness. The translation is very poor, and the reader never loses the consciousness of reading a German book. It is not divided into chapters, there are no page headings, no table of contents, no index, and what may be called the editing of the book is extremely faulty. This will quite prevent its ever being a popular book.

Spinoza, " the God-intoxicated MTan": a Short Account of his Life and Philosophy. By WILliam JoB Collins, B.Sc., M.D., \&c. Enfield: Meyers, Brookes, and Co. 1889.This little pamphlet contains an interesting sketch of the life, character, and teachings of a philosopher whose history and writings are still comparatively little known in this country. The author is probably right in attributing much that is distinctive in the nature and utterances of Spinoza to the influence of early personal and hereditary associations. Born of a Jewish family domiciled in Spain under the Moors, but afterwards exiled and established among the free and energetic Hollanders, he had on his side many circumstances favourable to the development of a mind at once artistic and philosophical, not wanting in worldly shrewdness, butremarkably sincere and disinterested. His frugality was conspicuous, and his unselfish devotion to principle came out in a pleasing light in his refusal, not only of honours which involved a retraction of his opinions, but of emoluments, like the legacy of De Vries, which he felt to be superfluous. In the treatise before us his religious and philosophical views, derived from his "Ethics" and the "Tractatus Religio Politicus," are explained with considerable clearness. His idea of the nature of God as an essence pervading all things, if its very vagueness proclaims that nature to be unfathomable, at all events frees him from the imputation of atheism. Christ is to him a singularly perfect man, and something more. He is the Eternal and embodied Wisdom of God to whom the Divine Mind directly and habitually revealed itself. There is a good deal of truth in his observation respecting the separate but mutually com. patible spheres of faith and philosophy. The same might be said of his assertion that prophecy is a sort of skilled and often truthful imagination, and that miracles form a group of peculiar natural or not contra-natural phenomena. He justifies free thought in religion and in politics, and reasonably enough when we consider that he was himself most cautious in his freethinking and most free from dogmatism. This moderation in thought and statement is a mark of the sense of order which rules the mind of every great thinker; and it is, in our opinion, not the least notable point brought out by Dr. Collins in this brief history of a remarkable man. - Sinomia Chimico-farmacotecnica di Salvatore Di-Giorgi, Chimico-farmacista in Mazzara del Vallo. Milano, a spese dell' antore, 1889. - This little dictionary of chemical and pharmaceutical synonyms, though it does not refer to terms 